\title{
Modified Activated Carbon with Zinc Oxide Nanoparticles Produced from Used Tire for Removal of Acid Green 25 from Aqueous Solutions
}

\author{
Farzaneh Jahanbakhsh, Bahram Ebrahimi* \\ Department of Chemistry, Faculty of Science, Sanandaj Branch, Islamic Azad University, Sanandaj, Iran \\ Email address: \\ b_ebrahimi@iausdj.ac.ir (B. Ebrahimi)
}

\section{To cite this article:}

Farzaneh Jahanbakhsh, Bahram Ebrahimi. Modified Activated Carbon with Zinc Oxide Nanoparticles Produced from Used Tire for Removal of Acid Green 25 from Aqueous Solutions. American Journal of Applied Chemistry. Vol. 4, No. 1, 2016, pp. 8-13. doi: 10.11648/j.ajac.20160401.12

\begin{abstract}
Modified activated carbon with zinc oxide nanoparticles $(\mathrm{ZnO}-n)$ as carbonaceous adsorbents was prepared by chemical and heat treatment of the used tire in $\mathrm{N}_{2}$ atmosphere. Heat impregnation method was used to modifying the activated carbon with $\mathrm{ZnO}-n$. In fact, Chemical activation, carbonization and heat activation of raw material were toke place in the presence of $\mathrm{ZnO}-n$. The produced carbon sample before modification show specific surface area $\left(\mathrm{S}_{\mathrm{BET}}\right) 19.271 \mathrm{~m}^{2} \mathrm{~g}^{-1}$ and pour volume $(\mathrm{Vp})$ of $0.273 \mathrm{~mL} \mathrm{~g}^{-1}$ and after modification the cited parameters were $90.469 \mathrm{~m}^{2} \mathrm{~g}^{-1}$ and $0.427 \mathrm{~mL} \mathrm{\textrm {g } ^ { - 1 }}$ respectively. The SEM images of adsorbent materials later and after impregnation showed excellent differences that lead to increasing the sorption properties related to non-modified activated carbon adsorbent. The prepared samples were studied as adsorbents for removal acid green 25 in aqueous solutions. Amount of adsorbent, dye concentration, time of process and $\mathrm{pH}$ of aqueous solutions as effective parameters were optimized. Modified adsorbent showed better results than the non-modified adsorbent and sorption capacity using the Langmuir isotherm was 111.3 and $306.8 \mathrm{mg} \mathrm{g}^{-1}$ for acid green 25 sorption on non-modified and modified adsorbent respectively. This study showed the potential ability of used tire as abundant raw material to production of activated carbon adsorbent and modification of it with Zno- $n$ to increase the sorption properties.
\end{abstract}

Keywords: Adsorbent, Activated Carbon, Zinc Oxide, Nanoparticles, Acidic Dyes

\section{Introduction}

Recycling and converting of used materials to high added value products is the best method to face with them. Recycling has many advantages such as environmental protection, construction of new career opportunities, and protection from loses of resources. Thus developing of sustainable and environmentally safe recycling processes is one of the big interests in research groups.

Tire is one of the much used materials in modern life. The EU, the USA and Japan together were responsible for the disposal of a total of 5 million tons of scrap tires per year. Accumulation of used tires in any places lead to many problems such as providing breeding place for mosquitoes and vermin causing serious disease and affecting human health, fire hazards, and providing harmful and undesirable odors and vapors in atmosphere $[1,2]$.

Recent developments in controlling pyrolysis reactions provide the foundation for production pyrolysis products from used tires. Several fundamental studies have reported that carefully controlled tire pyrolysis can produce of activated carbon as carbonaceous adsorbent materials [3-5]. The potential of these products to adsorption various pollutants has been investigated and found to be very successful, thus recently a serious research interest has been formed in this field. These carbonaceous adsorbents have been used to adsorb phenols and p-chlorophenols [3], dyes [6], butane and natural gas [7].

Nano particles are very interesting material with diverse properties to add the structure of activated carbon. Indeed, nano particles maybe enhance the adsorption capacity, change in thermodynamic model of adsorption or kinetic of process. Because of unique characteristics, it has been used to modifying and enhancing adsorptive, catalytic, and selectivity properties of carbon active [8-10]. In this study, we focused on production of activated carbon from waste tire and modification the product with $\mathrm{ZnO}-n$ to investigation the 
changes in adsorption properties for remove acid green 25 from aqueous solutions.

\section{Materials and Methods}

\subsection{Chemicals}

Waste tire was collected and as precursor raw material. $\mathrm{ZnO}-n$ particles were purchased from nano Gostar Co. with average $50 \mathrm{~nm}$ of particle size. Acid green 25 was purchased from Alvan Co. (Hamedan, Iran) with high purity. Phosphoric acid $\left(\mathrm{H}_{3} \mathrm{PO}_{4}\right)$, hydrochloric acid $(\mathrm{HCl})$ and sodium hydroxide $(\mathrm{NaOH})$ were purchased from Merck Co. (Darmstadt, Germany). Phosphoric acid was used as chemical activator reagent. Hydrochloric acid and sodium hydroxide $\left(0.1 \mathrm{~mol} \mathrm{~L}^{-1}\right)$ to adjust the $\mathrm{pH}$ of solutions were used. Aqueous stock standard solutions of acid green 25 as acidic dye at concentrations $400 \mu \mathrm{g} \mathrm{mL}^{-1}$ were prepared by the dissolution of the proper amount in deionized and distilled water. Working standard solutions were prepared daily through serial dilutions of the stock solution with double distilled water prior to analysis. The concentrations of all dyes were determined at maximum of wavelengths based on respective calibration curve obtained at the optimum conditions.

\subsection{Instruments}

The samples were weighted using an analytical balance (Citizen, CY 204, Poland). Isotope hot plate stirrer (Fisher Scientific, USA), was used for stirring. Carbonization and heat activation of prepared precursor material was done in electrical furnace/reactor with high capability temperature provision up to $1200^{\circ} \mathrm{C}$ and making of inert N2 atmosphere (Azar furnace, TF5 1250, Iran). The shape and surface morphology of samples were investigated by field emission scanning electron microscope (FESEM, Hitachi S4160, Japan) under an acceleration voltage of $15 \mathrm{kV}$. The specific surface area was measured by the BET method (Coulter, model SA3100, USA) with N2 chemi sorptions. A laboratory centrifuge (Heraeus, Labofuge 400 model, Germany) was used to accelerate the phase separation. The $\mathrm{pH}$ measurements were done using $\mathrm{pH} /$ Ion meter model-682 (Metrohm, Switzerland) and absorption studies were carried out using Jusco (Japan) UV-Visible spectrophotometer model V-570.

\subsection{Methods}

\subsubsection{Production Method of Adsorbents}

To production of activated carbon modified with $\mathrm{ZnO}-n$, the collected used tires were cut to small particles with $0.2-$ $0.3 \mathrm{~cm}$ of average diameter and washed with distilled water to remove any pollutants. After drying, $12 \mathrm{~g}$ of prepared tire sample add to $120 \mathrm{~g}$ of phosphoric acid $(85 \% \mathrm{w} / \mathrm{w})$ with 1 : 10 proportion on the magnetic stirrer with $1000 \mathrm{rpm}$. Then the $0.4 \mathrm{~g}$ of Zno- $n$ were gently added to mixture and stirred for 3 hours. Then the mixture was embed in ceramic container and transferred to electrical furnace/reactor under
$\mathrm{N}_{2}$ flow gas $\left(400 \mathrm{~cm}^{3} \mathrm{~min}^{-1}\right)$. To carbonization and heat activation of raw material in the presence of nano particles, the temperature was set to $350^{\circ} \mathrm{C}$ for 3 hours, then increase to $750^{\circ} \mathrm{C}$ for $30 \mathrm{~min}$. After naturally cool down, the prepared modified activated carbon neutralized with $\mathrm{NaOH}$ solution $\left(0.5 \mathrm{~mol} \mathrm{~L}^{-1}\right)$ under sonication for $20 \mathrm{~min}$ and washed with distilled water. Finally, the sample dried in oven to elimination of any $\mathrm{H}_{2} \mathrm{O}$ molecules at $110^{\circ} \mathrm{C}$ for 24 hours. With exactly same process the non-modified activated carbon produced without presence of Zno- $n$ particles.

\subsubsection{Adsorption Capacity}

In a batch system, the adsorption experiments of acid green 25 have been done on the surface of modified and non-modified adsorbents. The effective parameters such as the amount of adsorbent, equilibrium time, dye concentration and $\mathrm{pH}$ have been optimized. In the wavelength of maximum absorption $(640 \mathrm{~nm})$, the absorptions have determined before and after the contact of dye with adsorbents. To calculation of dye remove percent, the equation 1 has been used. Where $C_{0}$ is the initial concentration $\left(\mathrm{mg} \mathrm{L}^{-1}\right)$ and $\mathrm{C}_{\mathrm{t}}$ is the concentration at any time $\left(\mathrm{mg} \mathrm{L}^{-1}\right)$.

Equation 1 Dye remove $\%=\mathrm{C}_{0}-\mathrm{C}_{\mathrm{t}} / \mathrm{C}_{0}$.

In the perfect equilibrium state, the adsorption isotherms can be used to determine the adsorption model of solute on the surface of adsorbent. Different isotherms have been derived and used such as Langmuir, Frondlich, Temkin and so on. Langmuir and Frondlich isotherms are classic and famous to description the monolayer and multilayer of adsorption respectively. The well-known equation 2 has been used to calculation the amount of solute that adsorbed to adsorbents and finally calculation the parameters of isotherm models.

Equation $2 \mathrm{q}_{\mathrm{e}}=\left(\mathrm{C}_{0}-\mathrm{Ce}\right) \mathrm{v} / \mathrm{w}$.

Where $\mathrm{q}_{\mathrm{e}}, \mathrm{v}$ and $\mathrm{w}$ are the amount of solute that adsorbed to adsorbent $\left(\mathrm{mg} \mathrm{g}^{-1}\right)$, the volume of solution $(\mathrm{L})$ and the mass of used adsorbent $(\mathrm{g})$ respectively.

\section{Results and Dissections}

\subsection{The Structure of Produced Adsorbents}

Produced activated carbon adsorbents (modified and nonmodified) investigated by SEM and BET $\mathrm{N}_{2}$ adsorption. SEM images give us good information about the surface morphology and size of created porosities in micro and nano materials. Also $\mathrm{N}_{2}$ adsorption/desorption BET isotherm is very useful to determine the surface area and other parameters of adsorbents. Figure 1 show the SEM images of produced activated carbon samples. As can be seen the presence of $\mathrm{ZnO}-n$ particles lead to interesting state in the surface morphology of modified sample. The nano particle, it seems to be that fill the unevenness of surface of adsorbent and surface with higher homogeneity and uniform of porosity have formed. In fact, the amount of adsorption sites that is accessible to solutes is increased. 

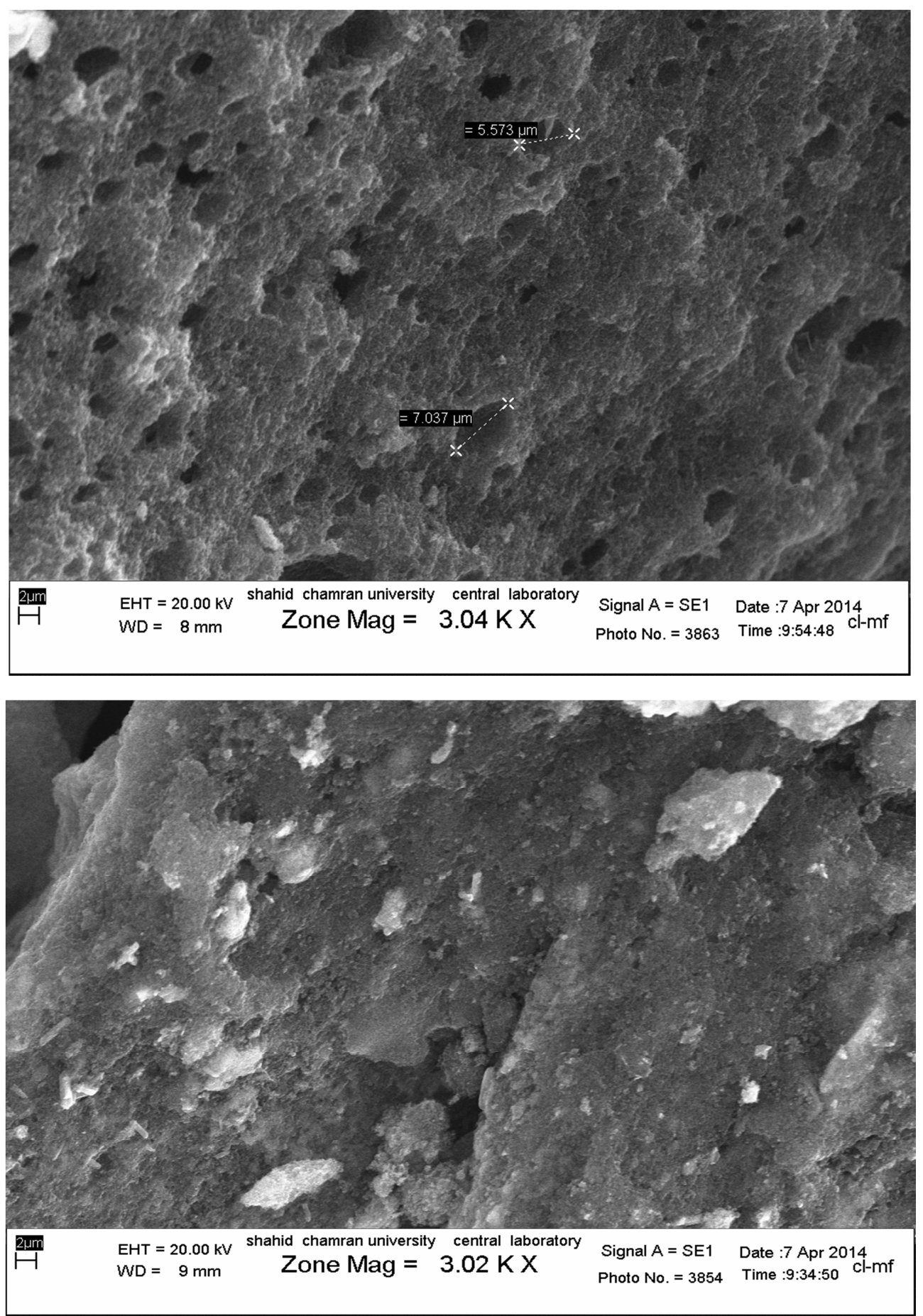

Fig. 1. SEM images of produced activated carbon modified (up) and non-modified (down).

Specific surface of produced adsorbents and some other property such as average pore volume and average pore diameter have accessible by adsorption/desorption of $\mathrm{N}_{2}$ based on well-known isotherms such as BET. Table 1 show the obtained results of BET adsorption/desorption experiments.

Table 1. Data obtained from Adsorption/desorption experiment of $N_{2}$ by BET isotherm on the adsorbents.

\begin{tabular}{llllll}
\hline \multicolumn{2}{l}{ Produced Adsorbent } & & & & \\
\hline Non-modified & & Modified & & \\
\hline $\mathbf{S}_{\text {BET }}\left(\mathbf{m}^{2} \mathbf{g}^{-1}\right)$ & Total pore volume $\left(\mathbf{C m}^{\mathbf{3}} \mathbf{g}^{-1}\right)$ & $\mathbf{V}_{\mathbf{m}}\left(\mathbf{C m}^{\mathbf{3}} \mathbf{g}^{-1}\right)$ & $\mathbf{S}_{\text {BET }}\left(\mathbf{m}^{\mathbf{2}} \mathbf{g}^{-1}\right)$ & Total pore volume $\left(\mathbf{C m}^{\mathbf{3}} \mathbf{g}^{-1}\right)$ & $\mathbf{V}_{\mathbf{m}}\left(\mathbf{C m}^{3} \mathbf{g}^{-1}\right)$ \\
\hline 90.469 & 0.4271 & 20.792 & 19.271 & 0.2738 & 4.530 \\
\hline
\end{tabular}


The results show that modified activated carbon by $\mathrm{ZnO}-n$ particles has better property in all parameters specifically in surface area $\left(\mathrm{S}_{\mathrm{BET}}\right)$. On the other hand the presence of $\mathrm{ZnO}-n$ particles in process lead to improve the characteristics of adsorbent.

\subsection{Application of Produced Adsorbents}

Produced adsorbents used to elimination of acid green 25 from aqueous solutions. The effective parameters optimized and in the optimum conditions the adsorption capacity calculated.

Optimization of effective parameters.

The effective parameters on adsorption toke care and optimized. For this purpose, the $40 \mathrm{ml}$ of dye with known concentration was prepared and different amount of adsorbent add to them and dye removal percent calculated at vary time of contact and $\mathrm{pH}$ of solutions based on one parameter at one time optimization method.

Amount of adsorbent.

Amount of adsorbent is one of the important factors in removal process of analytes based on adsorption method. Indeed, adsorbent with high adsorption capacity can be removal of solutes in low quantity and do not need to high amount of it. To investigation the effect of quantity of adsorbent, based on cited method, the absorption of dye solutions determined in $\chi_{\max }$ and dye removal percent was calculated. Figure 2 show the obtained results.

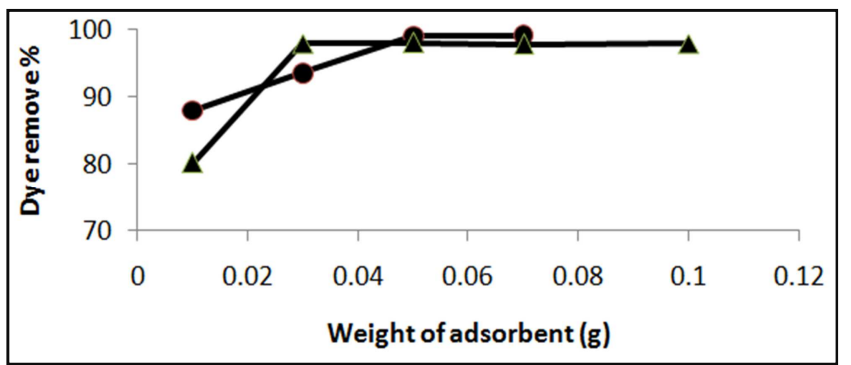

Fig. 2. The effect of amount of adsorbent on the removal of acid green 25 from $40 \mathrm{ml}$ of aqueous solution ( $\boldsymbol{\Delta}$ modified and $\bullet$ non- modified adsorbent).

As can be seen the required amount of modified adsorbent $(0.03 \mathrm{~g})$ is less than non-modified $(0.05 \mathrm{~g})$ to achieve quantitative remove of dye. This result may be related to higher surface area of this adsorbent.

\section{Contact time.}

The contact time between adsorbent and solute in solution phase is very important parameter in adsorption process specifically in batch state. In fact, mass transfer is timeconsuming phenomenon and hence adsorption of solute does not complete at low times. So investigation of time effect is necessary. Figure 3 show the effect of this parameter on the removal of acid green 25 .

The results show that the kinetic of adsorption process with modified adsorbent is faster than related to nonmodified adsorbent. It seems that the $\mathrm{ZnO}-n$ fills the dipper proses and active sites more accessible to acid green 25 molecules in the surface of modified adsorbent.

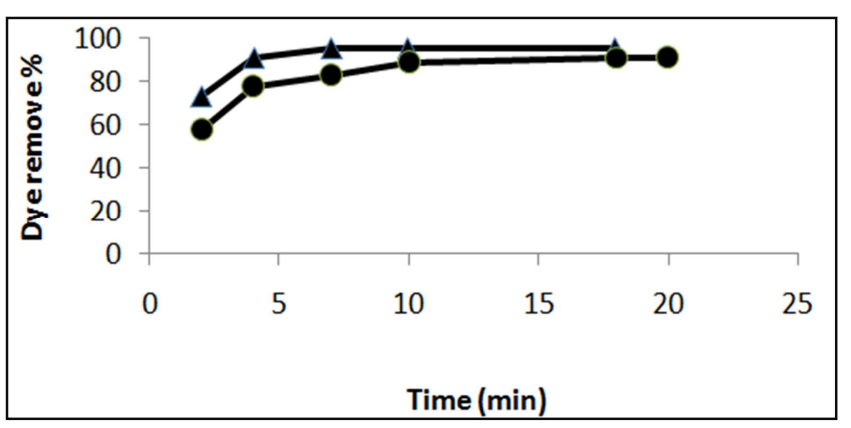

Fig. 3. The effect of contact time on the removal of acid green 25 from $40 \mathrm{ml}$ of aqueous solution at optimum amount of adsorbents ( $\mathbf{\Delta}$ modified and $\bullet$ non-modified adsorbent).

$p H$.

The $\mathrm{pH}$ solution can be affected on the adsorption efficiency of adsorbent. Because, the studied solute (acid green 25) has acidic property due to existence two sulfonic groups (figure 4) and also the surface of activated carbon can be affected by $\mathrm{pH}$ of solution. Thus the $\mathrm{pH}$ effect was investigated by adjustment it by $\mathrm{HCl}$ and $\mathrm{NaOH}$ solutions. Figure 5 show the effect of $\mathrm{pH}$ on the dye removal. The results show that in acidic and neutral solution the adsorption of acid green is high and in alkali medium the dye removal is reduced. Thus the $\mathrm{pH}$ of solution adjusted in neutral range.

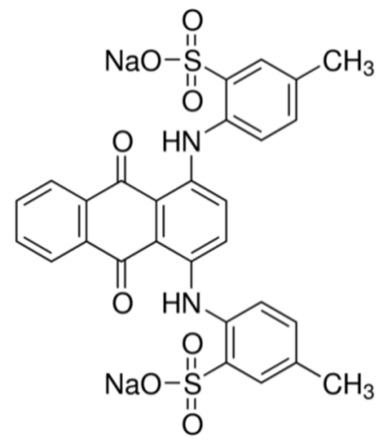

Fig. 4. The molecular structure of acid green 25.

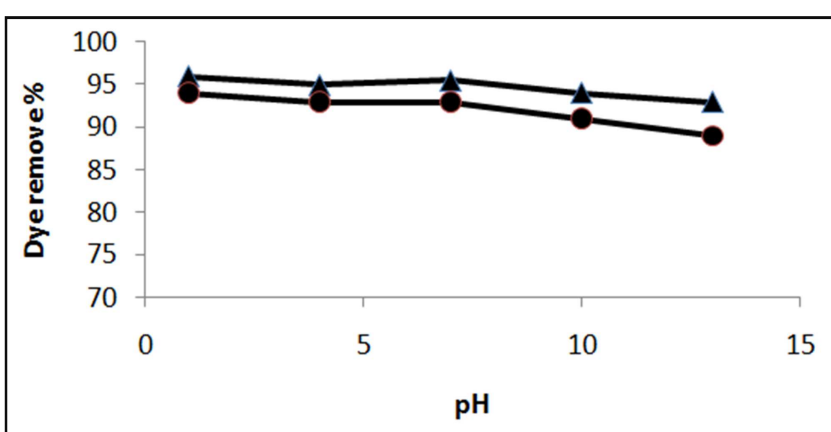

Fig. 5. The effect of $p H$ of solution on the removal of acid green 25 from 40 $\mathrm{ml}$ of aqueous solution at optimum amount of adsorbents and contact time ( $\Delta$ modified and $\bullet$ non modified adsorbent).

Dye concentration.

The maximum of adsorption capacity of adsorbent determine the maximum concentration of solute can be 
adsorbed. The experiments have done in different concentration of acid green 25 to determine the maximum adsorption capacity of produced adsorbents. Figure 6 show the obtained results.

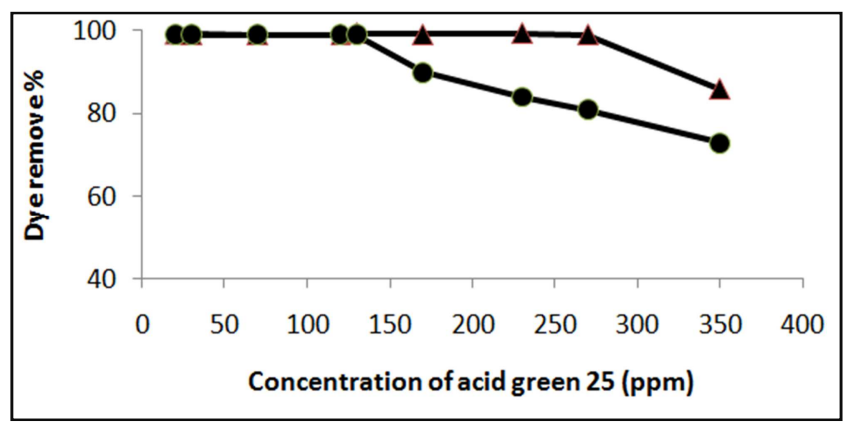

Fig. 6. The effect of dye concentration on the removal of solute from $40 \mathrm{ml}$ of aqueous solution at optimum amount of adsorbents, contact time and $\mathrm{pH}(\mathbf{\Delta}$ modified and $\bullet$ non modified).

Table 2. Optimum conditions of sorption acid green 25 by two produced adsorbent.

\begin{tabular}{lll}
\hline Parameters & $\begin{array}{l}\text { Non-modified } \\
\text { adsorbent }\end{array}$ & Modified adsorbent \\
\hline Contact time $(\mathrm{min})$ & 18 & 7 \\
Amount of adsorbent $(\mathrm{g})$ & 0.05 & 0.03 \\
$\mathrm{pH}$ & 7 & 7 \\
Dye concentration $(\mathrm{ppm})$ & 130 & 270 \\
\hline
\end{tabular}

The results show that the modified adsorbent has higher adsorption capacity than non-modified to sorption the studied dye. The maximum of dye concentration can be treated with modified is $270 \mathrm{ppm}$ and $130 \mathrm{ppm}$ with non-modified adsorbent respectively. Table 2 shows the optimum conditions. All data show that the modification process of activated carbon produced from used tire lead to increase the properties of adsorbent.

\subsection{Adsorption Isotherm of Acid Green 25}

In the complete equilibrium state of adsorption process, the adsorption isotherm can be descripting the model of solute and give the thermodynamic information about process. Many adsorption models was introduced and used in these studies. But Langmuir and Freundlich isotherms are well known between of themes. Langmuir isotherm as ideal adsorption thermodynamic model signifies of monolayer adsorption of molecules of solutes in the surface adsorption sites. In other way, Freundlich isotherm implies the multi layers adsorption take place in any adsorption sites of adsorbent in different layers. Equations 3 and 4 show the Langmuir and Freundlich models.

Equation $3 \mathrm{Ce} / \mathrm{q}_{\mathrm{e}}=1 / \mathrm{Q}^{\circ} \mathrm{b}+1 / \mathrm{Q}^{\circ}(\mathrm{Ce})$

Where $b$ is exponentially proportional to the heat of adsorption and related to the adsorption intensity and $\mathrm{Q}^{\circ}$ is monolayer adsorption capacity.

Equation $4 \log \mathrm{q}_{\mathrm{e}}=\log \mathrm{k}_{\mathrm{F}}+1 / \mathrm{n} \log \mathrm{Ce}$

Where $\mathrm{K}_{\mathrm{F}}$ is constant that show the real capacity adsorption of adsorbent and $1 / \mathrm{n}$ signifies the intensity of solute adsorption.

Adsorption isotherm was obtained by shaking the adsorbent of fixed doses and the adsorbate solution containing varied concentrations of acid green 25 for $24 \mathrm{~h}$. Table 3 show the results from fitting of obtained data at complete equilibrium state of adsorption at constant temperature for non-modified and modified adsorbents.

Table 3. Parameters of Langmuir and Frundlich isotherms for adsorption of acid green 25 onto adsorbents.

\begin{tabular}{|c|c|c|c|c|c|c|}
\hline \multirow{2}{*}{ Adsorbent } & \multicolumn{3}{|c|}{ Langmuir isotherm } & \multicolumn{3}{|c|}{ Freundlich isotherm } \\
\hline & $Q \circ\left(\mathrm{mg} \mathrm{g}^{-1}\right)$ & b $\left(\mathrm{L} \mathrm{mol}^{-1}\right)$ & $\mathbf{r}^{2}$ & $K_{F}\left(m g^{-1}\right)$ & $\mathbf{n}$ & $\mathbf{r}^{2}$ \\
\hline Non-modified & 111.3 & 1.03 & 0.8731 & 98.0 & 2.32 & 0.9964 \\
\hline Modified & 306.8 & 1.45 & 0.9932 & 78.6 & 2.98 & 0.8329 \\
\hline
\end{tabular}

The obtained data show the differences between adsorption models of none and modified adsorbents. These results may be attributed to filling the proses of non-modified activated carbon lead to adsorption sites formed in surface of adsorbent. Thus the monolayer adsorption is more likely to take place on surface of modified adsorbent.

\section{Conclusion}

The using of waste tires as raw material to production of new materials such as activated carbon adsorbent with useful properties is very interesting and practical. The results show that produced activated carbon from this raw material has good property to removal one of the frequently used acid dye (acid green 25) from aqueous solution. Also modification of adsorbent with $\mathrm{ZnO}-\mathrm{n}$ particles leads to sorption and structural properties of them. The method of modification is very simple and not need to specific conditions and nano particles will introduce to activated carbon structure and change the micro and macro properties of adsorbent.

\section{References}

[1] Williams PT, Bottrill RP., Sulfur-polycyclic aromatic hydrocarbons in tyre pyrolysis oil, Fuel 1995; 74 (5): 736-42.

[2] B. Acevedo, C. Barriocanal, Properties and performance of mesoporous activated carbons from scrap tyres, bituminous wastes and coal, Fuel, 2015; 151 (1): 83-90.

[3] V. K. Gupta, A. Nayak, S. Agarwal, I. Tyagi, Potential of activated carbon from waste rubber tire for the adsorption of phenolics: Effect of pre-treatment conditions, J. Coll. Inter. Sci., 2014; 417 (1): 420-430.

[4] N. Striūgas, K. Zakarauskas, G. Stravinskas, V. Grigaitienè, Comparison of steam reforming and partial oxidation of biomass pyrolysis tars over activated carbon derived from waste tire, Catalysis Today, 2012; 196, 67-74. 
[5] T. A. Saleh, V. K. Gupta, Processing methods, characteristics and adsorption behavior of tire derived carbons: A review, Advan. Coll. Inter. Sci., 2014; 211, 93-101.

[6] B. Acevedo, R. P. Rocha, M. F. R. Pereira, J. L. Figueiredo, C. Barriocanal, Adsorption of dyes by ACs prepared from waste tyre reinforcing fibre. Effect of texture, surface chemistry and pH, J. Coll. Inter. Sci., 2015; 459, 189-198.

[7] T. A. Brady, M. R. Abadi, M. J. Rood, Applications for activated carbons from waste tires: natural gas storage and air pollution control, Gas Sep. \& Pur., 1996; 10, 97-102.

[8] J. A. Orozco, J. Rene Mendez, T. J. Bandosz, Reactive adsorption of $\mathrm{SO} 2$ on activated carbons with deposited iron nanoparticles, J. Hazar. Mat., 2013; 246, 300-309.

[9] Y. A. Shaban, M. A. El Sayed, A. A. El Maradny, Photocatalytic degradation of phenol in natural seawater using visible light active carbonmodified (CM)-n-TiO2 nanoparticles under UV light and natural sunlight illuminations, Chemosphere, 2013; 91, 307-313.

[10] N. Barrabés, J. Just, A. Dafinov, F. Medina, J. L. G. Fierro, J. E. Sueiras, P. Salagre, Y. Cesteros, Catalytic reduction of nitrate on $\mathrm{Pt}-\mathrm{Cu}$ and $\mathrm{Pd}-\mathrm{Cu}$ on active carbon using continuous reactor: The effect of copper nanoparticles, Appl. Catal. B: Environmental, 2006; 62, 77-85. 